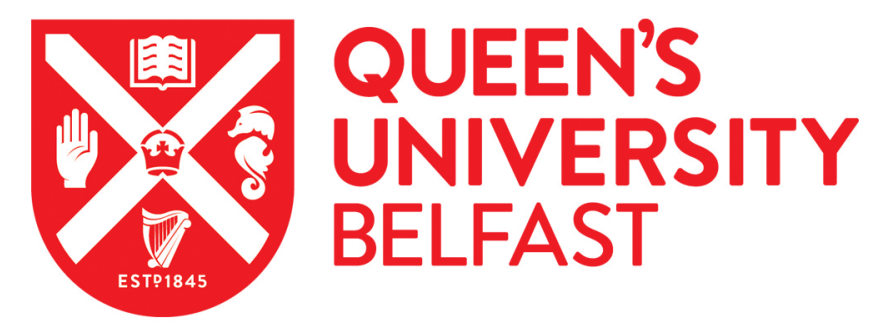

\title{
The effect of androgen deprivation therapy on body composition in men with prostate cancer systematic review and meta analysis
}

Haseen, F., Murray, L., Cardwell, C., O'Sullivan, J., \& Cantwell, M. (2010). The effect of androgen deprivation therapy on body composition in men with prostate cancer systematic review and meta analysis. Journal of Cancer Survivorship, 4(2), 128-139. https://doi.org/10.1007/s11764-009-0114-1

Published in:

Journal of Cancer Survivorship

Queen's University Belfast - Research Portal:

Link to publication record in Queen's University Belfast Research Portal

\section{General rights}

Copyright for the publications made accessible via the Queen's University Belfast Research Portal is retained by the author(s) and / or other copyright owners and it is a condition of accessing these publications that users recognise and abide by the legal requirements associated with these rights.

Take down policy

The Research Portal is Queen's institutional repository that provides access to Queen's research output. Every effort has been made to ensure that content in the Research Portal does not infringe any person's rights, or applicable UK laws. If you discover content in the Research Portal that you believe breaches copyright or violates any law, please contact openaccess@qub.ac.uk. 


\title{
The effect of androgen deprivation therapy on body composition in men with prostate cancer: Systematic review and meta-analysis
}

\author{
Farhana Haseen • Liam J. Murray • \\ Chris R. Cardwell • Joe M. O'Sullivan • \\ Marie M. Cantwell
}

Received: 17 September 2009 / Accepted: 22 December 2009 /Published online: 21 January 2010

(C) Springer Science+Business Media, LLC 2010

\begin{abstract}
Introduction The use of androgen deprivation therapy (ADT) in the treatment of prostate cancer is associated with changes in body composition including increased fat and decreased lean mass. Limited information exists regarding the rate and extent of these changes. This systematic review was conducted to determine the effects of ADT on body composition in prostate cancer patients.

Methods Literature searches were conducted on MEDLINE, EMBASE and Web of Science for studies until January 2009. Only longitudinal studies that examined ADT and body composition in prostate cancer patients were included. Data were extracted on body weight, BMI, percentage of fat mass and lean body mass.

Results Sixteen studies (14 cohorts and 2 RCTs) met the inclusion criteria. Pooled data, calculated according to a random effects model, showed that ADT increased \% body fat by on average $7.7 \%$ (95\% CI 4.3, 11.2, from seven studies,
\end{abstract}

F. Haseen · L. J. Murray • C. R. Cardwell • M. M. Cantwell Cancer Epidemiology and Prevention Research Group, Centre for Public Health, Queen's University Belfast,

Belfast, Northern Ireland, UK

J. M. O'Sullivan

Centre for Cancer Research and Cell Biology, Queen's University

Belfast, and the Northern Ireland Cancer Center,

Belfast, Northern Ireland, UK

F. Haseen $(\bowtie)$

Queen's University Belfast,

Centre for Public Health, Mulhouse Building,

Grosvenor Rd,

Belfast, Northern Ireland BT12 6BJ, UK

e-mail: fhaseen01@qub.ac.uk
$P<0.0001)$ and decreased \% lean body mass by on average $-2.8 \%$ (95\% CI $-3.6,-2.0$, from six studies, $P<0.0001)$ but for both there was marked heterogeneity between studies (I2=99\% I2=73\%, respectively). Similarly, body weight (2.1\%, $P<0.0001$ from nine studies) and BMI $(2.2 \%, P<$ 0.0001 , from eight studies) increased significantly. More extensive changes were seen with longer duration of treatment.

Conclusions Substantial increases in fat and declines in lean mass were observed in prostate cancer patients treated with ADT. Lifestyle changes or suitable interventions to minimize the effect of ADT on body composition need to be investigated.

Implications for cancer survivors Prostate cancer survivors should be made aware of the side effect of treatment on body composition and further work is required to determine what interventions can minimize the impact of ADT on body composition and therefore what evidence based advice they should be provided with. In general, though recommendation of a healthy diet and moderate exercise is reasonable.

Keywords Body composition · ADT · Prostate cancer . Systematic review

\section{Introduction}

Androgen deprivation therapy (ADT) is increasingly used as an essential component in the treatment of prostate cancer. It is often used as initial sole therapy in advanced or metastatic disease and in combination with radiotherapy or surgery in the localised or locally advanced setting [1]. The number of prescriptions of ADT for 
treating prostate cancer in the UK increased from 33,000 in 1987 to 470,000 in 2004 [2]. Reduction of testosterone to castrate levels (androgen deprivation) can be achieved by either surgical (orchidectomy) or medical castration [using Luteinizing hormone-releasing hormone analogues (LHRHa) or Luteinizing hormone-releasing hormone antagonists (LHRHant)], with or without anti-androgens [3]. Androgens, in particular testosterone, play an essential role in men's health. Testosterone is needed for normal male development, muscle strength, and bone mineralization, and has haemopoietic as well as sexual and reproductive functions [4]. Moreover, serum testosterone concentrations correlate positively with muscle mass and negatively with fat mass; consequently weight and fat mass increase and lean mass decreases with ADT [5]. These unfavourable changes in body composition associated with ADT may contribute to the fatigue, decreased physical functioning, emotional distress and lower overall quality of life experienced in this patient group [6, 7]. Moreover, ADT induced obesity may increase the risk of cardiovascular disease, adult onset of diabetes mellitus, hypertension, stroke, dyslipidemia, osteoarthritis and some other cancers [8]. Aging is accompanied by important changes in the endocrine system, characterized by decreased testicular function with a decline in testosterone levels. Given that prostate cancer affects older men, it can be expected that ADT related side-effects could exacerbate age-related weight gain and loss of muscle mass, further compromising muscle strength, physical and psychological functioning, independent living, morbidity and mortality.

When used in the advanced or metastatic setting, ADT has an initial response rate greater than $80 \%$ with a median duration of response of 12-24 months after which Castration Resistant Prostate Cancer (CRPC) emerges [3]. A number of randomized trials have demonstrated that ADT used in combination with radiotherapy can lead to improved survival rates compared with radiotherapy alone [9-11]. An improvement in 10-year survival favouring surgery plus ADT compared to radical prostatectomy alone has also been reported [12]. As a consequence, men may live for substantial periods on ADT or post-ADT treatment and the long term consequences of body composition changes associated with ADT treatment are of increasing importance e.g., muscle mass and bone density reduction may increase the risk of falls and fractures [13]. Effective strategies are required to minimise the body composition changes association with ADT but it is first necessary to robustly document these changes, especially in relation to duration and type of treatment. Therefore, we performed a systematic review and meta-analysis of longitudinal studies to determine the influence of routinely prescribed ADT on body composition in prostate cancer patients. In addition, we sought to synthesize the evidence on body composition associated with varying durations and forms of ADT.

\section{Methods}

Articles searched

The search strategy was developed with the help of a medical librarian to identify potentially relevant studies. The electronic databases MEDLINE, EMBASE and Web of Science were systematically searched for longitudinal studies of prostate cancer patients treated with ADT and body composition as the outcome measure. Each database was searched from its inception until January 2009. There were no restrictions regarding the dates of publication, study design, language, or country of origin. We used search terms Medical Subject Heading (MESH) terms and key words related to prostate cancer (prostate cancer, prostatic neoplasms, prostate carcinoma, cancer of prostate), androgen deprivation therapy (androgen antagonists, androgens, androgen deprivation, orchidectomy, gonadotropin-releasing hormone, GnRH agonists, luteinizing hormone, testosterone hormone antagonists, LHRH antagonist, LHRH analogues, antiandrogen) and body composition (body composition, body mass index, body fat mass, total fat, lean body mass, muscle, abdomen fat, body weight, obesity). The reference list of retrieved articles was also checked for relevant studies.

\section{Study selection}

Duplicates were excluded and two independent reviewers (FH, MMC) screened the titles and abstracts of identified studies to assess relevance. Papers deemed potentially relevant were obtained, and the same independent reviewers reviewed the full papers for inclusion.

\section{Inclusion criteria}

We included primary research studies that reported data changes in body composition occurring after ADT use in prostate cancer patients. The measures of body composition included were body weight, BMI, percentage fat mass and percentage lean mass. Studies were checked for the following criteria: 1) the study was a full report published in a peer reviewed journal; 2) the study was longitudinal; 3) prostate cancer was histologically confirmed; 4) prostate cancer patients received one or more hormone treatments (e.g., LHRH, GnRH, anti-androgen) or had undergone orchidectomy; 5) the study provided data on the change in at least one measure of body 
composition following ADT. Articles were included if they met all five criteria.

\section{Exclusion criteria}

Review articles were not included. Studies were excluded if they presented data pertaining to animal models or included treatment methods other than ADT or combined treatment (radiology/chemotherapy/prostatectomy with ADT) or if a change in body composition could not be calculated. Several case control studies identified through the search compared body composition in men with prostate cancer to a control population e.g., prostate cancer patients not receiving ADT or healthy men. As these studies did not provide baseline (before treatment) information on body composition, changes in body composition could not be examined and the studies were therefore excluded.

\section{Data extraction}

Information on patients, methods, interventions and outcomes was extracted from the original reports by two independent reviewers (FH, MMC) onto pre-designed and tested forms. Disagreements were resolved by consensus. If multiple studies presented findings from the same cohort, we used these data only once in our analysis. We extracted the following data from each study: participant characteristics (e.g., age, cancer stage), treatment received (e.g., form, dose, frequency, and duration of hormone therapy) and clinical outcomes (e.g., weight, BMI, percentage of fat mass and lean body mass). Because the terms lean body mass and fat-free mass are typically used interchangeably in the literature, we reported fat-free mass and lean body mass data as a single category of lean body mass. Similarly, we reported body mass and body weight as a single category of body weight.

In order to collate the information reported we selected the mean and SE of the percentage change in measures of body composition. If the percentage change in weight or BMI was not available we calculated the difference between the initial and final weight or BMI, expressed as a percentage of the baseline value, and imputed a SD of $4.59 \%$ and $4.53 \%$ for weight and BMI respectively. These SD values were a conservative estimate based on the upper limit of all of the observed results [14]. This calculation was not required for percentage fat mass and lean mass as they were reported as a percentage change in the selected articles. In studies that reported percentage changes in body composition measures as medians and ranges, these were converted to mean and SE according to the methods reported by Hozo et al. [15]. Where RCTs compared ADT to anti-androgen, we included the data from the ADT treatment group in the overall analysis examining the effect of ADT on body composition.
Statistical analysis

Mean percentage changes (SE) in body composition measures in each study were pooled using random effects models after heterogeneity among the trials was considered. All results were calculated with $95 \%$ confidence intervals (CIs). Sensitivity analyses were performed and assessed inter-study heterogeneity to evaluate the robustness of the results. Each study was removed individually to evaluate its effect on the summary estimate. The heterogeneity among study results for each of the summary effects is presented by showing the chi-square (and associated $P$ value) and $I^{2}$ statistics. In predetermined subgroup analysis we stratified studies by duration and type of treatment and evaluated sources of heterogeneity. The analyses were performed Review Manager (RevMan) software, version 5 (Cochrane Collaboration). SPSS, version 17 was used to plot the studies in scattered diagram to present the percentage of change over the months of ADT treatment.

Subgroup analyses based on treatment characteristics, including: type of treatment provided (LHRH/GnRH analogue and combination with anti-androgen) and duration of intervention ( $\leq 3, \leq 6$ and $>6$ months), were also completed.

\section{Results}

\section{Studies retrieved}

Figure 1 summarizes the results of our literature search. A total of 1,126 titles from MEDLINE, EMBASE and Web of Science databases were reviewed. From the electronic search we retrieved 121 articles for full-text evaluation and found one additional title from our bibliographic

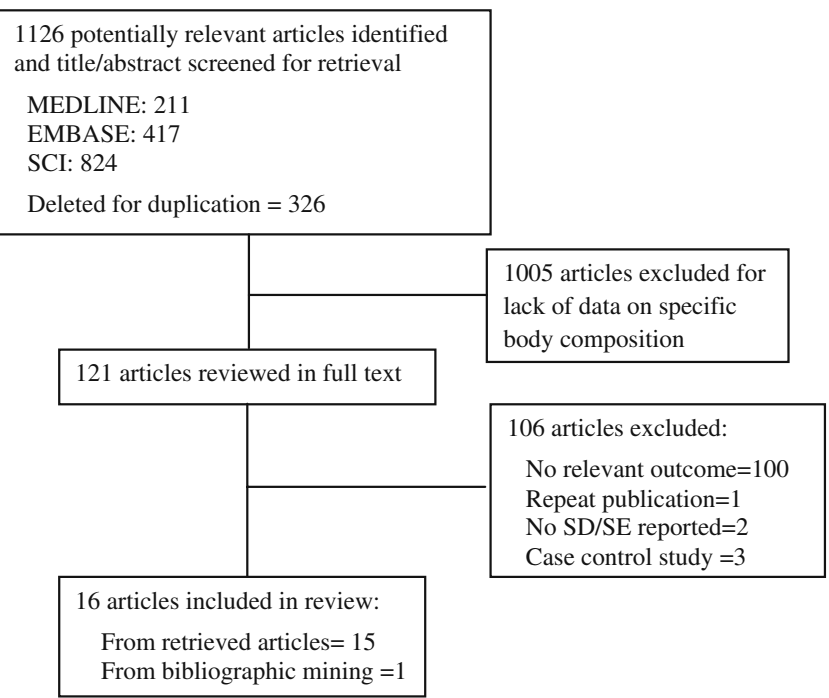

Figure 1 Study flow diagram. 
search. Smith et al. [16] presented data on one treatment group of patients from a trial and included data on BMI, which was not presented in the report of the trial [17]. Data from both papers were therefore included in the relevant meta-analyses.

\section{Study characteristics}

Sixteen longitudinal studies were included in the systematic review, 14 cohort studies [7, 16, 18-29] and two RCTs [17, 30]. Both RCTs were the continuation phase of a randomized design comparing the efficacy of two types of hormone therapy (LHRH analogue vs. anti-androgen). The studies were conducted in several different countries including Italy, Belgium, Poland, United Kingdom, Australia, Japan and the United States. The studies were conducted using a convenience sample of patients rather than a random selection. Dropout rates were infrequently reported but appeared to be low; only three studies $[17,21,27]$ reported loss to followup ranging from 2 to $20 \%$.

\section{Patient characteristics}

Information from 573 patients was available for inclusion in this meta-analysis from 16 studies. These studies included a wide range of cancer stages including localized, advanced, recurrent, metastatic, non-metastatic, lymph node positive but not bone metastases, stage A to D and stage T2-T4 [31] (Table 1). The study populations were comparable in age and body composition at baseline, most were elderly [mean age $69.8(\mathrm{SD}=8.5)$ ] and overweight [mean BMI $27.0(\mathrm{SD}=3.7)$ $\mathrm{kg} / \mathrm{m}^{2}$ and mean weight $79.8(\mathrm{SD}=12.8) \mathrm{kg}$ ] (Table 2). However, the length of time of treatment and the frequency of body composition measurements varied across studies. Moreover, the populations differed between studies with respect to other clinical characteristics and co-morbidities e.g., evidence of cardiac or cerebrovascular disease, history of kidney, or liver disease; problems with bone metabolism or osteoporosis; history of diabetes, endocrine disorders, or inflammatory disease.

\section{Treatment characteristics}

The type of ADT used varied considerably between studies (Table 1) and evaluated the changes in body composition with a single agent, LHRH analogue or a combination regimen with anti-androgen.

\section{Change in body weight and BMI}

Figure 2 shows the changes of body weight and BMI. These studies provided data on weight change for 289 patients with periods of treatment varying from 1 to 12 months. All studies reported an increase in weight among participants (range $0.6-5.4 \%$ ), which was statistically significant in five studies [23, 24, 26, 27, 29]. In studies wherein subject body weights were measured at different time points ( 1 and 3 months; 6 and 12 months; 2, 6 and 12 months) [18, 24, 25, 29], we considered the change from baseline to the last time point in our pooled analyses and in more than half of these studies the duration was 1 year. The pooled mean percentage change in weight was $2.1 \%$ (95\% confidence interval 1.4 $2.9 \%, P<0.00001)$, but this estimate incorporated significant heterogeneity (Fig. 2).

Eight studies [7, 16, 18, 20, 24, 27-29], involving 208 patients treated with ADT for between 3 and 12 months, provided data on change in BMI (Fig. 2). All except one [20] showed that use of ADT resulted in an increase in BMI and in four studies the increases were statistically significant $[16,24,27,29]$. The pooled estimate of mean percentage change in BMI, although showing considerable heterogeneity, was $2.2 \%$ (95\% confidence interval 1.2 $3.1 \%, P<0.0001$ ) (Fig. 2).

Changes in percentage fat mass and lean mass

Mean percentage change in fat mass, as measured by dual energy x-ray absorptiometry (DEXA), was presented in seven studies [17, 19, 21, 22, 26-28] (Fig. 3). Treatment duration varied from 3 to 12 months, but all studies showed statistically significant gains in fat mass irrespective of the duration or type of treatment received. The pooled estimate of mean change in fat mass was $(7.7 \%$; $\mathrm{CI}, 4.3-11.2 \%, P<$ 0.0001 ), however heterogeneity was high. A total of 325 patients were included in this meta-analysis (Fig. 3).

Six studies [17, 22, 26-28, 30], involving 260 patients and with treatment periods ranging from 3 to 24 months, reported the $\%$ change in percentage of lean mass (Table 2 ). Loss of lean mass was reported in all of the studies and the pooled estimate was $-2.8 \%(95 \% \mathrm{CI},-3.6 \%$ to $-2.0 \%, P<$ 0.00001) (Fig. 3).

\section{Subgroup analyses}

Subgroup analyses were carried out according to duration ( $\leq 3$ months, $\leq 6$ months, and $>6$ months) and type of treatment (LHRH analogue or combination of LHRH with anti-androgen) (Table 3). Increases in body weight and BMI were seen at 3 months and were more pronounced (approximately twice as large) with treatment periods in excess of 6 months. A significant increase in weight was evident even within one month of treatment $(1.96 \%$ increase; 95\% CI 0.54-3.39) in two studies [24, 25]. At 12 months the changes were highly significant $(P<$ $0.00001)$ for all measurements of body composition; weight 


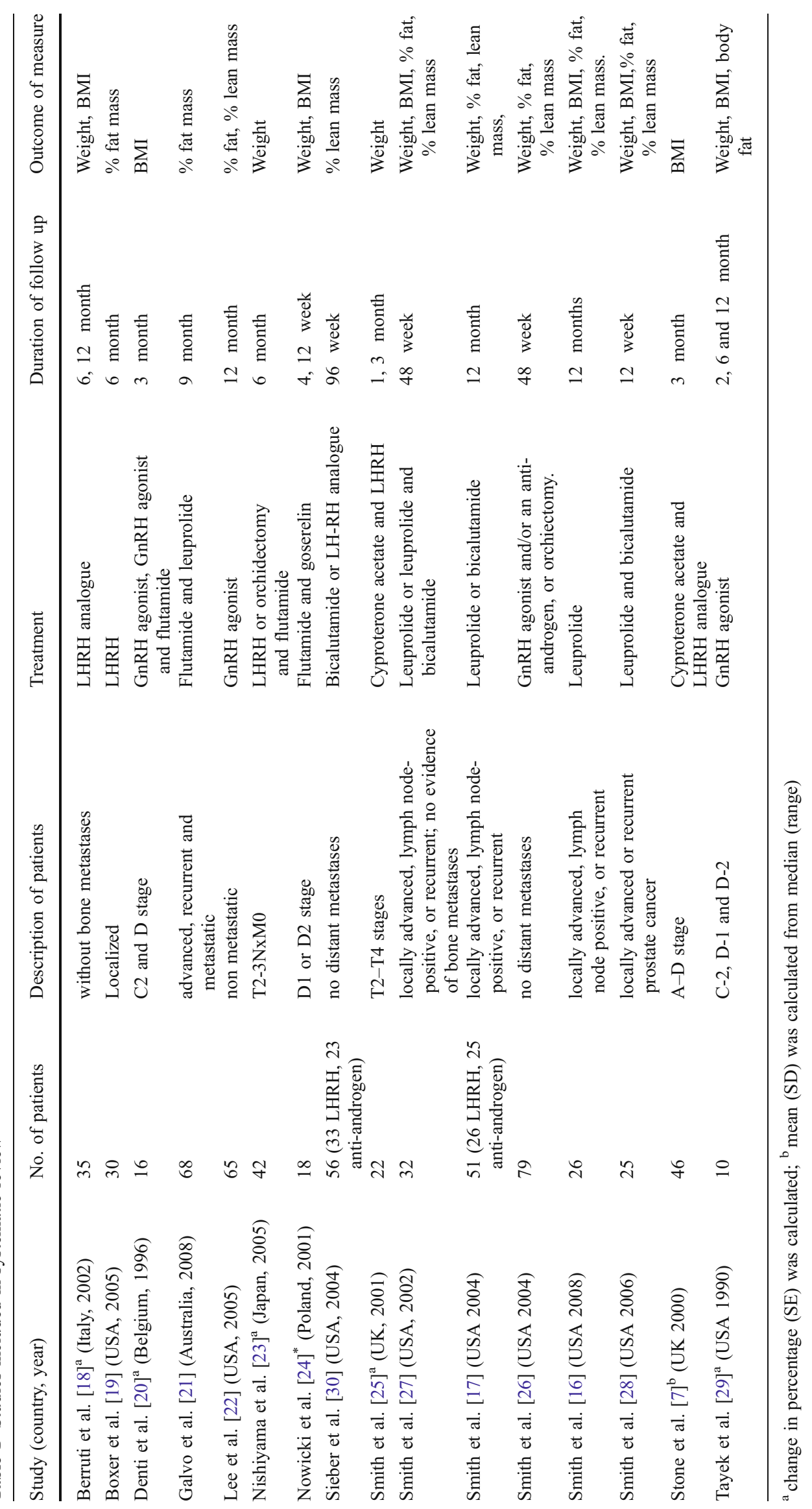


Table 2 Baseline characteristics of participants

\begin{tabular}{|c|c|c|c|c|c|}
\hline Studies & Mean Age (SD), y & Mean weight (SD), $\mathrm{kg}$ & Mean BMI (SD), $\mathrm{kg} / \mathrm{m} 2$ & $\%$ fat mass, $\mathrm{kg}$ & $\%$ lean mass, $\mathrm{kg}$ \\
\hline Berruti et al. [18] & $75 \pm 6.3$ & $73.4 \pm 11.7$ & $25.9 \pm 3.6$ & NR & NR \\
\hline Boxer et al. [19] & $71.9 \pm 7.1$ & NR & $26.8 \pm 3.1$ & $29.8 \pm 6.4$ & NR \\
\hline Denti et al. [20] & $73 \pm 6.6$ & NR & $25.7 \pm 3.6$ & NR & NR \\
\hline Galvo et al. [21] & $73.5 \pm 8.3$ & NR & $27.1 \pm 3.8$ & $25.8 \pm 4.95$ & NR \\
\hline Lee et al. [22] & $66 \pm 10$ & NR & $27.5 \pm 3.4$ & $27.1 \pm 4.9$ & $69.7 \pm 4.7$ \\
\hline Nishiyama et al. [23] & $69 \pm 6.3$ & $60.1 \pm 8.4$ & NR & NR & NR \\
\hline Nowicki et al. [24] & $67 \pm 9$ & $70.4 \pm 12.2$ & $24.7 \pm 3.6$ & NR & NR \\
\hline Sieber et al. [30] & $75.2 \pm 7.3$ & $83.9 \pm 15.3$ & NR & NR & NR \\
\hline Smith et al. [25] & $67 \pm 8$ & $83 \pm 14$ & NR & NR & NR \\
\hline Smith et al. [27] & $66 \pm 11.3$ & $81.9 \pm 9.6$ & $26.9 \pm 2.8$ & $26.4 \pm 6.2$ & $70.3 \pm 5.7$ \\
\hline Smith et al. [17] & $65 \pm 10$ & NR & $27.1 \pm 3.4$ & $25.1 \pm 4.8$ & NR \\
\hline Smith et al. [26] & $71 \pm 9$ & $87.9 \pm 15.1$ & $28.4 \pm 4.4$ & $28.0 \pm 7.1$ & $68.7 \pm 7.1$ \\
\hline Smith et al. [16] & $65 \pm 10$ & $83.3 \pm 10.7$ & $27.1 \pm 3.4$ & $25.1 \pm 4.8$ & NR \\
\hline Smith et al. [28] & $68 \pm 10$ & $89.5 \pm 13.5$ & $29.1 \pm 4$ & $28.7 \pm 6$ & $68.1 \pm 5.5$ \\
\hline Stone et al. [7] & $69 \pm 6.3$ & NR & $25.4 \pm 3.7$ & NR & NR \\
\hline Tayek et al. [29] & $74 \pm 4$ & $74.5 \pm 12$ & $25.2 \pm 2.5$ & NR & NR \\
\hline
\end{tabular}

NR- not reported

Figure 2 Effect of ADT on mean changes in percentage of body weight and BMI.
$\%$ of change in body weight

\begin{tabular}{|c|c|c|c|c|c|}
\hline Studies & $\begin{array}{l}\text { Number } \\
\text { of patients }\end{array}$ & $\begin{array}{l}\text { Duration } \\
\text { (month) }\end{array}$ & $\begin{array}{c}\text { Study } \\
\text { weight }\end{array}$ & $\begin{array}{l}\text { Change in percentage } \\
(95 \% \mathrm{Cl})\end{array}$ & $\begin{array}{l}\text { Mean Difference } \\
95 \% \mathrm{CI} \text { Random }\end{array}$ \\
\hline Berruti et al (18) & 35 & 12 & $12.0 \%$ & $1.60[0.07,3.13]$ & - \\
\hline Nishiyama et al (23) & 42 & 6 & $12.9 \%$ & $0.83[-0.56,2.22]$ & \\
\hline Nowicki et al (24) & 18 & 3 & $8.5 \%$ & $3.84[1.72,5.96]$ & \\
\hline Smith et al (25) & 22 & 3 & $9.5 \%$ & $2.41[0.49,4.33]$ & $\longrightarrow$ \\
\hline Smith et al (27) & 32 & 12 & $11.7 \%$ & $2.40[0.83,3.97]$ & $\longrightarrow$ \\
\hline Smith et al (17) & 26 & 12 & $10.4 \%$ & $3.20[1.44,4.96]$ & $\longrightarrow$ \\
\hline Smith et al (26) & 79 & 12 & $16.2 \%$ & $1.80[0.82,2.78]$ & $\rightarrow$ \\
\hline Smith et al (28) & 25 & 3 & $13.1 \%$ & $0.60[-0.77,1.97]$ & $\square$ \\
\hline Tayek et al (29) & 10 & 12 & $5.7 \%$ & $5.37[2.53,8.21]$ & \\
\hline Total $(95 \% \mathrm{Cl})$ & & & $100.0 \%$ & $2.14[1.35,2.94]$ & \\
\hline \multicolumn{6}{|c|}{ Heterogeneity: $\mathrm{Chi}^{2}=17.59, \mathrm{df}=8(\mathrm{P}=0.02) ; \mathrm{I}^{2}=55 \%$} \\
\hline
\end{tabular}

$\%$ of change in BMI

\begin{tabular}{|c|c|c|c|c|c|c|}
\hline Studies & $\begin{array}{r}\text { Number } \\
\text { of patient }\end{array}$ & $\begin{array}{l}\text { Duration } \\
\text { (month) }\end{array}$ & $\begin{array}{c}\text { Study } \\
\text { weight }\end{array}$ & $\begin{array}{l}\text { Change in percentage } \\
(95 \% \mathrm{Cl})\end{array}$ & $\begin{array}{l}\text { Mean Di } \\
95 \% \mathrm{CI}\end{array}$ & $\begin{array}{l}\text { ifference } \\
\text { Random }\end{array}$ \\
\hline Berruti et al (18) & 35 & 12 & $14.0 \%$ & $1.93[0.42,3.44]$ & & \\
\hline Denti et al (20) & 16 & 3 & $10.2 \%$ & $-0.39[-2.60,1.82]$ & & \\
\hline Nowicki et al (24) & 18 & 3 & $10.7 \%$ & $4.05[1.95,6.15]$ & & \\
\hline Smith et al (27) & 32 & 12 & $13.6 \%$ & $2.40[0.83,3.97]$ & & \\
\hline Smith et al (28) & 25 & 3 & $16.0 \%$ & $0.80[-0.38,1.98]$ & & \\
\hline Smith et al (16) & 26 & 12 & $12.5 \%$ & $3.10[1.34,4.86]$ & & \\
\hline Stone et al (7) & 46 & 3 & $15.2 \%$ & $1.57[0.26,2.88]$ & & \\
\hline Tayek et al (29) & 10 & 12 & $7.8 \%$ & $5.16[2.36,7.96]$ & & \\
\hline Total $(95 \% \mathrm{Cl})$ & & & $100.0 \%$ & $2.15[1.16,3.14]$ & & \\
\hline \multicolumn{5}{|c|}{$\begin{array}{l}\text { Heterogeneity: } \mathrm{Chi}^{2}=19.11, \mathrm{df}=7(\mathrm{P}=0.008) ;\left.\right|^{2}=63 \% \\
\text { Test for overall effect: } Z=4.25(P<0.0001)\end{array}$} & $\begin{array}{lll}1 & 1 \\
-4 & -2 & 0\end{array}$ & 0 \\
\hline
\end{tabular}


Figure 3 Effect of ADT on mean percentage of changes of $\%$ of fat mass and $\%$ of lean mass.
$\%$ of change in fat mass

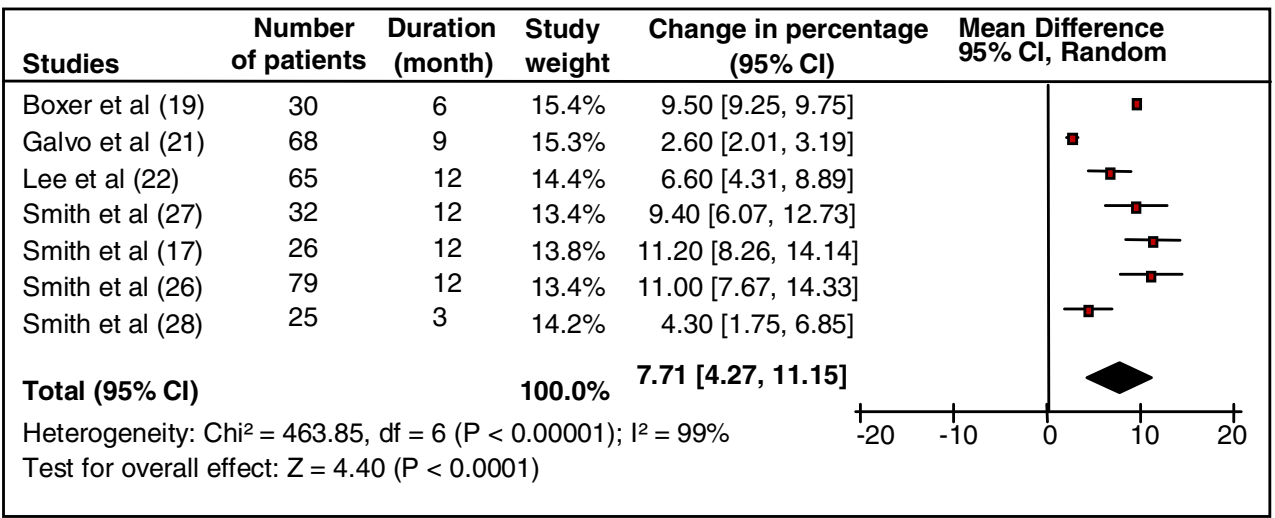

$\%$ of change in lean mass

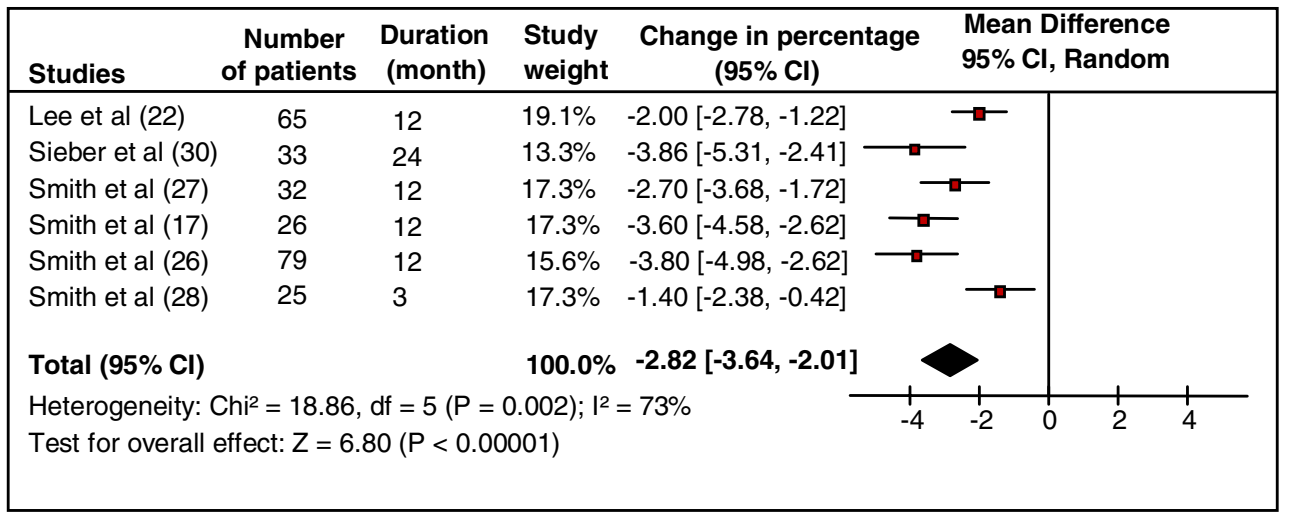

increased by $2.46 \%$ (95\% CI 1.50, 3.42), BMI increased $2.78 \%(95 \%$ CI 1.70, 3.86) and percentage fat increased by $9.39 \%$ (95\% CI 7.02, 11.75); and the percentage lean mass decreased by $3.0 \%(95 \% \mathrm{CI}-3.88,-2.32)$. The percentages of changes over the time period of treatment are presented in Fig. 4.

Body composition outcomes appeared to differ by treatment type. Less pronounced changes were reported in patients treated with combined androgen blockade rather than LHRH analogues monotherapy (Table 3), although these differences were not statistically significant. In two RCTs [17, 30], there was a greater decrease in mean percentage lean mass in the LHRH analogue treated patients compared to those treated with anti-androgen monotherapy. The pooled percentage change in lean mass was $-1.3 \%(95 \% \mathrm{CI}-2.5,-0.1)$ lower in the anti-androgen groups compared to LHRH analogue groups (data not shown).

\section{Sensitivity analyses}

A number of sensitivity analyses were performed including removal of each study one at a time, removal of the studies in which corrections were made to obtain the percentage change in weight/BMI, and removal of studies on the basis of treatment duration. In general, heterogeneity was reduced but not eliminated in these sensitivity analyses, and no important changes occurred in the pooled estimates of body composition measures.

\section{Discussion}

This meta-analysis examined the effects of ADT on body composition in men with prostate cancer and includes the results from 16 studies and 573 prostate cancer patients. The meta-analysis confirms that ADT adversely influences body composition, as it induces weight gain, increases BMI and fat mass and decreases lean body mass.

Our study is the first systematic review of published data from prospective studies on body composition changes in men undergoing ADT for prostate cancer. Similar results have been reported in cross-sectional studies of men with prostate cancer compared to age matched controls [32, 33]. We did not include such studies in our analyses, as the appropriateness of such comparison groups is questionable. In a 2-year prospective study, declines in lean body mass and increases in body fat were reported in prostate cancer patients receiving ADT compared with patients who were not and healthy controls [34]. These data were not included 
Table 3 Subgroup analysis of mean percentage changes in measures of body composition

\begin{tabular}{|c|c|c|c|}
\hline Outcome & No. of Studies & Pooled percentage change $(95 \% \mathrm{CI})$ & Heterogeneity \\
\hline \multicolumn{4}{|l|}{ Weight } \\
\hline \multicolumn{4}{|l|}{ Duration of treatment } \\
\hline$-<=3$ months & 4 & $1.27(0.33,2.20), P=0.008$ & $\mathrm{Chi}^{2}=2.29, P=0.51, \mathrm{I}^{2}=0 \%$ \\
\hline$-<=6$ months & 6 & $1.76(0.64,2.89), P=0.002$ & $\mathrm{Chi}^{2}=12.23, P=0.03, \mathrm{I}^{2}=59 \%$ \\
\hline$->6$ months & 5 & $2.37(1.54,3.20), P<0.0001$ & $\mathrm{Chi}^{2}=6.81, P=0.15, \mathrm{I}^{2}=41 \%$ \\
\hline \multicolumn{4}{|l|}{ Type of treatment } \\
\hline - LHRH & 3 & $3.10(1.18,5.01), P=0.002$ & $\mathrm{Chi}^{2}=5.69, P=0.06, \mathrm{I}^{2}=65 \%$ \\
\hline - LHRH and anti-androgen (Combination) & 6 & $1.76(0.97,2.62), P<0.001$ & $\mathrm{Chi}^{2}=9.23, P=0.06, \mathrm{I}^{2}=46 \%$ \\
\hline \multicolumn{4}{|l|}{ BMI } \\
\hline \multicolumn{4}{|l|}{ Duration of treatment } \\
\hline$-<=3$ months & 5 & $1.42(0.19,2.66), P=0.02$ & $\mathrm{Chi}^{2}=9.70, P=0.05, \mathrm{I}^{2}=59 \%$ \\
\hline$-<=6$ months & 6 & $1.60(0.44,2.75), P=0.007$ & $\mathrm{Chi}^{2}=13.60, P=0.02, \mathrm{I}^{2}=63 \%$ \\
\hline$->6$ months & 4 & $2.78(1.70,3.86), P<0.0001$ & $\mathrm{Chi}^{2}=4.30, P=0.23, \mathrm{I}^{2}=30 \%$ \\
\hline \multicolumn{4}{|l|}{ Type of treatment } \\
\hline - LHRH & 3 & $3.06(1.46,4.67), P=0.0002$ & $\mathrm{Chi}^{2}=4.11, P=0.13, \mathrm{I}^{2}=51 \%$ \\
\hline - LHRH and anti-androgen (Combination) & 5 & $1.65(0.46,2.85), P=0.007$ & $\mathrm{Chi}^{2}=11.10, P=0.03, \mathrm{I}^{2}=64 \%$ \\
\hline \multicolumn{4}{|l|}{$\%$ Fat mass } \\
\hline \multicolumn{4}{|l|}{ Type of treatment } \\
\hline - LHRH & 3 & $9.05(7.00,11.10), P<0.0001$ & $\mathrm{Chi}^{2}=7.40, P=0.02, \mathrm{I}^{2}=73 \%$ \\
\hline - LHRH and anti-androgen (Combination) & 4 & $6.60(2.57,10.62), P<0.0001$ & $\mathrm{Chi}^{2}=38.96, P<0.0001, \mathrm{I}^{2}=92 \%$ \\
\hline \multicolumn{4}{|l|}{$\%$ Lean mass } \\
\hline \multicolumn{4}{|l|}{ Type of treatment } \\
\hline - LHRH & 3 & $-3.07(-4.32,-1.82), P<0.0001$ & $\mathrm{Chi}^{2}=8.61, P=0.001, \mathrm{I}^{2}=77 \%$ \\
\hline - LHRH and anti-androgen (Combination) & 3 & $-2.60(-3.93,-1.28), P=0.0001$ & $\mathrm{Chi}^{2}=9.69, P=0.008, \mathrm{I}^{2}=79 \%$ \\
\hline
\end{tabular}

in our meta-analysis because baseline (pre-treatment) body composition measures were not available. However, the studies in our meta-analysis did not have a non-ADT comparison group. Therefore in part, the change in body composition reported may have resulted from normal aging rather than ADT. However, in a cross-sectional study, Basaria et al. [35] did not find any difference in total body fat mass in untreated prostate cancer patients and healthy controls matched for age. Similarly in prospective studies of healthy older men, fat mass and lean body mass were not altered after 2 or 3 years of treatment [34, 36]; suggesting that aging alone cannot account for the marked body composition changes observed in our reviewed studies.

Traditionally, ADT was reserved for patients with advanced stages of prostate cancer (metastasized to bone), however over the past 15 years it has become a component in the standard therapy for locally advanced prostate cancer both alone and in combination with radiotherapy [9, 37]. The number of prostate cancer patients receiving ADT is therefore increasing rapidly [2]. Prostate cancer patients are surviving for longer periods because of earlier diagnosis and treatment and the long-term consequence of ADT on body composition is becoming increasingly important. A high BMI or weight is thought to be a risk factor for the development of high-grade prostate cancer [38] and metastasis [39] and significantly decreases survival rates and life expectancy [39, 40]. Furthermore, a recent large observational study has indicated a relationship between an increased incidence of diabetes, coronary heart disease, myocardial infarction and sudden cardiac death with ADT [41]. The findings of this review collectively indicate the importance of maintaining optimal weight and body composition in prostate cancer patients during treatment with ADT.

It is well known that androgens modulate body composition by influencing lipid metabolism [27, 42], resulting in obesity. The marked increases in fat mass observed in prostate cancer patients suggest that androgen deprivation therapy may increase the risk of a variety of co-morbid conditions [8]. Moreover, reduced lean mass is directly associated with impairments and compromised physical functioning in older adults [43, 44]. In addition, the decline in lean mass would compromise the basal metabolic rate and hence energy requirement; further exacerbating the increase in fat mass associated with ADT. Therefore, strategies aimed at preserving lean mass 

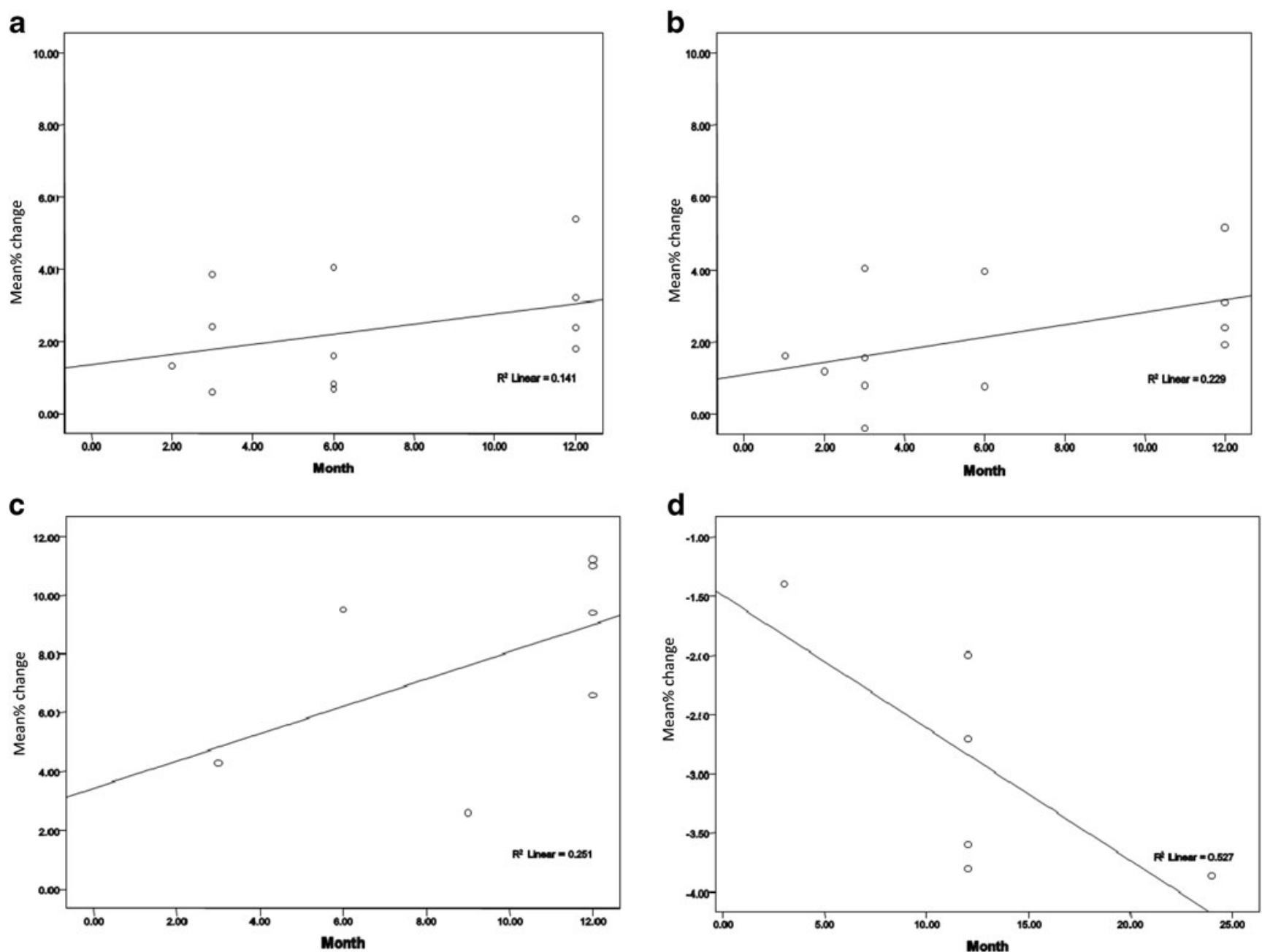

Figure 4 Mean percentage of change in body composition- (a) body weight, (b) BMI, (c) fat mass (d) lean mass over the months of treatment with ADT.

will also assist in attenuating the increase in fat mass. Resistance training has been reliably shown to be a safe and effective strategy to improve muscle mass and function in older adults [45], including the very old [46]. Experimental studies examining the role of exercise during ADT treatment for prostate cancer have shown that 10-20 weeks of exercise is an effective way to reduce fatigue, improve quality of life, increase muscular fitness, muscle strength, muscle thickness, functional performance and balance independent of induced changes in body composition [47-49]. In addition, 20 weeks exercise has been shown to preserve lean body mass and prevent an increase in fat mass in men undergoing ADT for prostate cancer [47]. Changes in dietary intake at the time of treatment may also help to counteract the changes in body composition associated with ADT, though dietary modification was not included in any intervention alongside exercise.
We found that a longer duration of ADT treatment independently predicted greater weight gain and fat accumulation but body composition changes appear to start very early after initiation of treatment. Smith et al. [25] reported weight gain from $84 \pm 14 \mathrm{~kg}$ at baseline to $85 \pm 14 \mathrm{~kg}$ at 1 month and decreased lean mass from $63.2 \pm 6.8 \mathrm{~kg}$ at baseline and $62.3 \pm$ $5.4 \mathrm{~kg}$ after 1 month $(P=0.003)$ of ADT in newly diagnosed prostate cancer patients. Similarly, Polish researchers [24] observed a significant increase in weight and BMI after just 4 weeks of treatment with weight increasing from $70.4 \pm 12.2$ to $71.4 \pm 12.6$ and BMI from $24.7 \pm 3.6$ to $25.1 \pm 3.7$ ( $P$ for both $<0.01)$. In follow up, approximately two-thirds $(66 \%)$ of the observed weight gains and $80 \%$ of observed changes in fat and lean mass were evident at 6 months [16]. Most of the trials in this review were for 12 months duration except Sieber et al. [30], wherein a considerable change in lean mass was noticed from 6 months and became more prominent by 24 months. Studies of a greater duration are 
needed to assess the long-term affect of ADT treatment considering evidence for adverse changes in body composition with continued treatment. Moreover countermeasures, such as age-appropriate exercise and low calorie diet, should be encouraged in this patient group from the beginning of treatment to help stabilise or even mitigate the rate of change in body composition that frequently occurs after induction of ADT.

In subgroup analysis, our pooled estimate showed that antiandrogen might offer an important advantage compared to LHRG analogue monotherapy in terms of changes in body weight, BMI, and percentage of fat mass and lean mass. These findings are consistent with the results of two RCTs $[17,30]$. Anti-androgen monotherapy is increasingly being used as an alternative to LHRH based ADT for the treatment of prostate cancer patients [50, 51]. This study showed anti-androgen (bicalutamide) resulted in an increase in testosterone level with excellent androgen blockade [52] and may, therefore, be expected to have a beneficial effect on body composition compared with LHRH based ADT. Anti-androgen monotherapy is approved to treat locally advanced prostate cancer in 55 countries; in the United States anti-androgen is only approved for use in combination with LHRH analogue [53]. In RCTs of men with non-metastatic prostate cancer, overall survival was similar for anti-androgen monotherapy and for either bilateral orchiectomy or treatment with a LHRH agonist [54-56]. Bicalutamide $150 \mathrm{mg}$ monotherapy also has been shown to have survival advantage in locally advanced patients in combination with radiotherapy [57]. Therefore, anti-androgen monotherapy appears to be a preferred treatment as an alternative to LHRHa for prostate cancer considering the changes in body composition in the locally advanced setting.

\section{Strength}

The strengths of this review include the application of wide search criteria to capture all potentially relevant articles. We only included prospective studies with body composition measured at both baseline and following ADT treatment and excluded cross-sectional studies that compared body composition in ADT treated prostate cancer patients to nonADT treated patients or non patient populations. Fat and lean body mass were measured by using the gold standard method, DEXA [58].

\section{Limitation}

Most of the study participants were white, and therefore observed changes in body composition may not be generalisable to other racial or ethnic groups. Inferences from our review regarding changes in body composition associated with ADT need to be considered in the context of inadequate adjustments of confounders in the primary studies. There was a dearth of information pertaining to e.g., physical activity and energy intake in the studies and none reported the adjusted results. However, changes in these factors may have influenced the body composition outcomes investigated. In general, the studies included were small and may have had inherent sample selection biases due to purposive sampling. As data was unavailable to determine the standard deviation of change from baseline and there was no correlation coefficient provided, the absolute change in mean and standard deviation could not be calculated [59].

\section{Clinical implications}

As this meta-analysis indicates, changes in body composition commence almost immediately after induction of ADT; oncologists should therefore consider early initiation of prophylactic measures to counteract the ensuing weight gain and reduction in lean mass which may have a negative impact on fitness, physical functioning, increasing the likelihood of fractures and related morbidities in this patient group. The option of combined or intermittent ADT or antiandrogen monotherapy may need to be taken into account where appropriate, considering the effect of LHRH monotherapy on body composition.

\section{Future research}

Larger prospective studies with longer follow-up are necessary to confirm the long-term effect of ADT on body composition with ADT. Measurements should be taken of body composition well as the subsequent biochemical and physiological changes in RCTs and other studies examining the effects of ADT. There is also a need for adequately powered RCTs to test the effectiveness of exercise and dietary interventions to minimise body composition changes and their sequelae in prostate cancer patients treated with ADT.

\section{Conclusions}

This review summarizes the best available evidence regarding the effects of ADT on body composition in prostate cancer patients. Significant increases in body weight, BMI, percentage body fat and declines in lean body mass were reported in studies of ADT where a wide range of prostate cancer patients were included. The changes occur early in treatment, become more pronounced with longer-term therapy and are more marked in patients treated with LHRH analogues rather than in combination with anti-androgens. There is a need to investigate strategies to reduce the adverse body composition changes associated with ADT in prostate cancer patients. 


\section{References}

1. Demers RY, Tiwari A, Wei J, Weiss LK, Severson RK, Montie J. Trends in the utilization of androgen-deprivation therapy for patients with prostate carcinoma suggest an effect on mortality. Cancer. 2001;92:2309-17.

2. Hussain S, Gunnell D, Donovan J, McPhail S, Hamdy F, Neal $\mathrm{D}$, et al. Secular trends in prostate cancer mortality, incidence and treatment: England and Wales, 1975-2004. BJU Int. 2008;101:547-55.

3. Gotkas S, Crawford ED. Optimal hormonal therapy for advanced prostatic carcinoma. Semin Oncol. 1999;26:162-73.

4. Morley JE. Testosterone and behavior. Clin Geriatr Med. 2003;19:605-16.

5. Vermeulen A, Goemaere S, Kaufman JM. Testosterone, body composition and aging. J Endocrinol Investig. 1999;22:110-6.

6. Herr HW, O'Sullivan M. Quality of life of asymptomatic men with nonmetastatic prostate cancer on androgen deprivation therapy. J Urol. 2000;163:1743-6.

7. Stone P, Hardy J, Huddart R, A'Hern R, Richards M. fatigue in patients with prostate cancer receiving therapy. Eur $\mathrm{J}$ Cancer. 2000;36:1134-41.

8. Burton BT, Foster WR, Hirsch J, Van Itallie TB. Health implications of obesity: an NIH Consensus Development Conference. Int J Obes. 1985;9:155-70.

9. Bolla M, Collette L, Blank L, Warde P, Dubois JB, Mirimanoff $\mathrm{RO}$, et al. Long-term results with immediate androgen suppression and external irradiation in patients with locally advanced prostate cancer (an EORTC study): a phase III randomised trial. Lancet. 2002;360:103-6.

10. Bolla M, Gonzalez D, Warde P, Dubois JB, Mirimanoff RO, Storme $\mathrm{G}$, et al. Improved survival in patients with locally advanced prostate cancer treated with radiotherapy and goserelin. N Engl J Med. 1997;337:295-300.

11. Pilepich MV, Winter K, Lawton CA, Krisch RE, Wolkov HB, Movsas B, et al. Androgen suppression adjuvant to definitive radiotherapy in prostate carcinoma-long-term results of phase III RTOG 85-31. Int J Radiat Oncol Biol Phys. 2003;61:1285-90.

12. Messing E, Manola J, Sarosdy M, Wilding G, Crawford ED, Trump D. Immediate hormonal therapy compared with observation after radical prostatectomy and pelvic lymphadenectomy in men with node positive prostate cancer: results at 10 years of EST 3886. April 29, 2003; AUA Annual Meeting, Chicago, [Abstract \#1480].

13. Shahinian VB, Kuo YF, Freeman JL, Goodwin JS. Risk of fracture after androgen deprivation for prostate cancer. $\mathrm{N}$ Engl $\mathrm{J}$ Med. 2005;352:154-64.

14. Potter J, Langhorne P, Roberts M. Routine protein energy supplementation in adults: systematic review. BMJ. 1998;317:495-501.

15. Hozo SP, Djulbegovic B, Hozo I. Estimating the mean and variance from the median, range and the size of a sample. BMC Med Res Methodol. 2005;5:13.

16. Smith MR, Lee H, McGovem F, Fallon MA, Goode M, Zietman $\mathrm{AL}$, et al. Metabolic changes during gonadotropin-releasing hormone agonist therapy for prostate cancer: differences from the classic metabolic syndrome. Cancer. 2008;112:2188-94.

17. Smith MR, Goode M, Zietman AL, McGovern FJ, Lee H, Finkelstein JS. Bicalutamide monotherapy versus leuprolide monotherapy for prostate cancer: effects on bone mineral density and body composition. J Clin Oncol. 2004;22:2546-53.

18. Berruti A, Dogliotti L, Terrone C, Cerutti S, Isaia G, Tarabuzzi R, et al. Changes in bone mineral density, lean body mass and fat content as measured by dual energy x-ray absorptiometry in patients with prostate cancer without apparent bone metastases given androgen deprivation therapy. J Urol. 2002;167:2361-7.
19. Boxer RS, Kenny AM, Dowsett R, Taxel P. The effect of 6 months of androgen deprivation therapy on muscle and fat mass in older men with localized prostate cancer. Aging Male. 2005;8:207-12.

20. Denti L, Pasolini G, Cortellini P, Ferretti S, Sanfelici L, Ablondi F, et al. Effects of androgen suppression by gonadotropinreleasing hormone agonist and flutamide on lipid metabolism in men with prostate cancer: focus on lipoprotein(a). Clin Chem. 1996;42:1176-81.

21. Galvao DA, Spry NA, Taaffe DR, Newton RU, Stanley J, Shannon $\mathrm{T}$, et al. Changes in muscle, fat and bone mass after 36 weeks of maximal androgen blockade for prostate cancer. BJU Int. 2008;102:44-7.

22. Lee H, McGovern K, Finkelstein JS, Smith MR. Changes in bone mineral density and body composition during initial and long-term gonadotropin-releasing hormone agonist treatment for prostate carcinoma. Cancer. 2005;104:1633-7.

23. Nishiyama T, Ishizaki F, Anraku T, Shimura H, Takahashi K. The influence of androgen deprivation therapy on metabolism in patients with prostate cancer. J Clin Endocrinol Metab. 2005;90:657-60.

24. Nowicki M, Bryc W, Kokot F. Hormonal regulation of appetite and body mass in patients with advanced prostate cancer treated with combined androgen blockade. J Endocrinol Investig. 2001;24:31-6.

25. Smith JC, Bennett S, Evans LM, Kynaston HG, Parmar M, Mason $\mathrm{MD}$, et al. The effects of induced hypogonadism on arterial stiffness, body composition, and metabolic parameters in males with prostate cancer. J Clin Endocrinol Metab. 2001;86:4261-7.

26. Smith MR. Changes in fat and lean body mass during androgendeprivation therapy for prostate cancer. Urology. 2004;63:742-5.

27. Smith MR, Finkelstein JS, McGovern FJ, Zietman AL, Anne Fallon M, Schoenfeld DA, et al. Changes in body composition during androgen deprivation therapy for prostate cancer. J Clin Endocrinol Metab. 2002;87:599-603.

28. Smith MR, Lee $H$, Nathan DM. Insulin sensitivity during combined androgen blockade for prostate cancer. J Clin Endocrinol Metab. 2006;91:1305-8.

29. Tayek JA, Heber D, Byerley LO, Steiner B, Rajfer J, Swerdloff RS. Nutritional and metabolic effects of gonadotropin-releasing hormone agonist treatment for prostate cancer. Metabolism. 1990;39:1314-9.

30. Sieber PR, Keiller DL, Kahnoski RJ, Gallo J, McFadden S. Bicalutamide $150 \mathrm{mg}$ maintains bone mineral density during monotherapy for localized or locally advanced prostate cancer. J Urol. 2004;171:2272-6.

31. Selly S, Donovan J, Faulkner A, Coast J, Gillatt D. Diagnosis, management and screening of early localised prostate cancer. Health Technol Assess. 1997;1(2):31-5.

32. Chen Z, Maricic M, Nguyen P, Ahmann FR, Bruhn R, Dalkin BL. Low bone density and high percentage of body fat among men who were treated with androgen deprivation therapy for prostate carcinoma. Cancer. 2002;95:2136-44.

33. Stoch SA, Parker RA, Chen L, Bubley G, Ko YJ, Vincelette A, et al. Bone loss in men with prostate cancer treated with gonadotropin-releasing hormone agonists. J Clin Endocrinol Metab. 2001;86:2787-91.

34. van Londen GJ, Levy ME, Perera S, Nelson JB, Greenspan SL. Body composition changes during androgen deprivation therapy for prostate cancer: a 2-year prospective study. Crit Rev Oncol Hematol. 2008;68:172-7.

35. Basaria S, Leib J, Tang AM, DeWeese T, Carducci M, Eisenberger $\mathrm{M}$, et al. Long-term effects of androgen deprivation therapy in prostate cancer patients. Clin Endocrinol (Oxf). 2002;56:779-86.

36. Snyder PJ, Peachey H, Hannoush P, Berlin JA, Loh L, Lenrow $\mathrm{DA}$, et al. Effect of testosterone treatment on body composition 
and muscle strength in men over 65 years of age. J Clin Endocrinol Metab. 1999;84:2647-53.

37. Messing EM, Manola J, Sarosdy M, Wilding G, Crawford ED, Trump D. Immediate hormonal therapy compared with observation after radical prostatectomy and pelvic lymphadenectomy in men with nodepositive prostate cancer. N Engl J Med. 1999;341:1781-8.

38. Gong EM, Neuhouser ML, Goodman PJ, Albanes D, Chi C, Hsing AW, et al. Obesity, diabetes, and risk of prostate cancer: results from the prostate cancer prevention trial. Cancer Epidemiol Biomarkers Prev. 2006;15:1977-83.

39. Gong Z, Agalliu I, Lin DW, Stanford JL, Kristal AR. Obesity is associated with increased risks of prostate cancer metastasis and death after initial cancer diagnosis in middle-aged men. Cancer. 2007;109:1192-202.

40. Efstathiou JA, Bae K, Shipley WU, Hanks GE, Pilepich MV, Sandler HM, et al. Obesity and mortality in men with locally advanced prostate cancer: analysis of RTOG 85-31. Cancer. 2007;110:2691-9.

41. Keating NL, O'Malley AJ, Smith MR. Diabetes and cardiovascular disease during androgen deprivation therapy for prostate cancer. J Clin Oncol. 2006;24:4448-56.

42. Arrer E, Jungwirth A, Mack D, Frick J, Patsch W. Treatment of prostate cancer with gonadotropin-releasing hormone analogue: effect on lipoprotein[a]. J Clin Endocrinol Metab. 1996;81:2508 11

43. Bassey EJ, Fiatarone MA, O’Neill EF, Kelly M, Evans WJ, Lipsitz LA. Leg extensor power and functional performance in very old men and women. Clin Sci (Lond). 1992;82:321-7.

44. Evans WJ. What is sarcopenia? J Gerontol A Bio Sci Med Sci. 1995;50:5-8.

45. Taaffe DR. Sarcopenia. Exercise as a treatment strategy. Aus Farm Physician. 2006;35:130-4.

46. Fiatarone MA, Marks EC, Ryan ND, Meredith CN, Lipsitz LA, Evans WJ. High-intensity strength training in nonagenarians. Effects on skeletal muscle. JAMA. 1990;263:3029-34.

47. Galvao DA, Nosaka K, Taaffe DR, Spry N, Kristjanson LJ, McGuigan MR, et al. Resistance training and reduction of treatment side effects in prostate cancer patients. Med Sci Sports Exerc. 2006;38:2045-52.

48. Culos-Reed SN, Robinson JL, Lau H, O'Connor K, Keats MR. Benefits of a physical activity intervention for men with prostate cancer. J Sport Exerc Psychol. 2007;29:118-27.

49. Segal RJ, Reid RD, Courneya KS, Malone SC, Parliament $\mathrm{MB}$, Scott $\mathrm{CG}$, et al. Resistance exercise in men receiving androgen deprivation therapy for prostate cancer. J Clin Oncol. 2003;21:1653-9.

50. See WA, Wirth MP, McLeod DG, Iversen P, Klimberg I, Gleason $\mathrm{D}$, et al. Bicalutamide as immediate therapy either alone or as adjuvant to standard care of patients with localized or locally advanced prostate cancer: first analysis of the early prostate cancer program. J Urol. 2002;168:429-35.

51. Iversen P, Tyrrell CJ, Kaisary AV, Anderson JB, Van Poppel H, Tammela TL, et al. Bicalutamide monotherapy compared with castration in patients with nonmetastatic locally advanced prostate cancer: 6.3 years of follow-up. J Urology. 2000;164:1579-82.

52. Verhelst J, Denis L, Van Vliet P, Van Poppel H, Braeckman J, Van Cangh $P$, et al. Endocrine profiles during administration of the new non-steroidal anti-androgen Casodex in prostate cancer. Clin Endocrinol (Oxf). 1994;41:525-30.

53. Loblaw DA, Virgo KS, Nam R, Somerfield MR, Ben-Josef E, Mendelson DS, et al. American Society of Clinical Oncology recommendations for the initial hormonalmanagementof androgen-sensitive metastatic, recurrent, or progressive prostate cancer. J Clin Oncol. 2004;22:2927-41.

54. Iversen P, Tyrrell CJ, Kaisary AV, Anderson JB, Baert L, Tammela $\mathrm{T}$, et al. Casodex (bicalutamide) 150-mg monotherapy compared with castration in patients with previously untreated nonmetastatic prostate cancer: results from two multicenter randomized trials at a median follow-up of 4 years. Urology. 1998;51:389-96.

55. Tyrrell CJ, Kaisary AV, Iversen P, Anderson JB, Baert L, Tammela $\mathrm{T}$, et al. A randomised comparison of Casodex (bicalutamide) $150 \mathrm{mg}$ monotherapy versus castration in the treatment of metastatic and locally advanced prostate cancer. Eur Urol. 1998;33:447-56.

56. Boccardo F, Rubagotti A, Barichello M, Battaglia M, Carmignani G, Comeri G, et al. Bicalutamide monotherapy versus flutamide plus goserelin in prostate cancer patients: results of an Italian Prostate Cancer Project study. J Clin Oncol. 1999;17:2027-38.

57. Tyrrell CJ, Payne H, See WA, McLeod DG, Wirth MP, Iversen P, et al. Bicalutamide (Casodex) $150 \mathrm{mg}$ as adjuvant to radiotherapy in patients with localised or locally advanced prostate cancer: results from the randomised Early Prostate Cancer Programme. Radiother Oncol. 2005;76:4-10.

58. Pietrobelli A, Heymsfield SB, Wang ZM, Gallagher D. Multicomponent body composition models: recent advances and future directions. Eur J Clin Nutr. 2001;55:69-75.

59. Higgins JPT, Green S, editor. Cochrane handbook for systematic reviews of interventions. Version 5.0.2, Section 16.1.3.2, September 2009. Available from: http://www.cochrane-handbook.org/ 